\section{Silver staining of spirochaetes in single tissue sections}

\author{
S. FAINE ${ }^{1}$ From the Division of Epidemiology, \\ Israel Institute for Biological Research, Ness \\ Ziona, Israel
}

Silver staining methods for identifying spirochaetes in tissue sections and smears should be specific, so that reticular and nerve fibres remain unstained and should not cause precipitates, so that the background is perfectly free from silver-stained granules. Preferably the tissue should be stained lightly or not at all, so that histological structure is preserved and counterstaining may be used. While the Dobell modification of the Levaditi procedure may satisfy these requirements for blocks of tissue (Carleton and Drury, 1957; Faine, 1957) it is often necessary and useft 1 for diagnostic or investigative purposes to perform staining procedures on single paraffin sections. Of the numerous methods available, all may suffer from precipitation or overstaining of spirochaetes or tissues or both. The procedure described below has been adapted from the modification of the Warthin-Starry method by Faulkner and Lillie (1945). The essential new departures are complete freedom from precipitate or from staining of reticular fibres, together with reproducibility, simplicity, and relative freedom from the need for empirical control of conditions.

\section{REAGENTS}

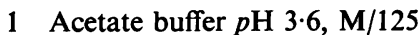

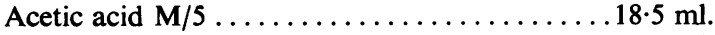

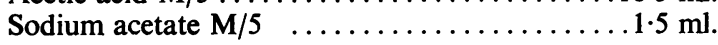
Make up to $500 \mathrm{ml}$. with deionized or double-glassdistilled water, i.e., $1 / 25$ dilution of $\mathrm{M} / 5$ solution. (2) Silver nitrate, $2 \%$ in acetate buffer, $p \mathrm{H}$ to 3.6 at $37^{\circ} \mathrm{C}$. and silver nitrate, $1 \%$ in acetate buffer, $p \mathrm{H}$ to $3 \cdot 6$, at $56^{\circ} \mathrm{C}$. (3) Five per cent gelatin in acetate buffer is melted at $56^{\circ} \mathrm{C}$. and dissolved. Do not overheat, $p \mathrm{H}$ to 3.6 at $37^{\circ} \mathrm{C}$. (4) Three per cent hydroquinone in acetate buffer is made up freshly. The shelf life is three to four days in a cold room. (5) Five per cent sodium thiosulphate ('hypo').

\section{METHOD}

1 Dewax and hydrate sections as usual, and rinse thoroughly in water to remove traces of alcohol. (2) Place in acetate buffer for two minutes. (3) Fill a light-proofed Coplin jar or other container with $1 \%$ silver nitrate at $56^{\circ} \mathrm{C}$., place in it the slide to be stained, and stand the container in a $56^{\circ}$ water-bath for 30 minutes. Make sure the water level is up to the top of the container (place the container inside a tin or beaker if necessary to achieve this). (4) Near the end of this time prepare the developer. Take 15 parts warm gelatin solution (at $37^{\circ} \mathrm{C}$.) Add slowly from a pipette 3 parts warm $2 \% \mathrm{AgNO}_{3}$

'Address: The Department of Bacteriology, University of Sydney, Australia.

Received for publication 27 May 1964. taking about one minute and stirring continuously with the tip of the pipette (for a standard Coplin jar use $60 \mathrm{ml}$. gelatin, add $12 \mathrm{ml} . \mathrm{AgNO}_{3}$ ). Keep in the dark at $37^{\circ} \mathrm{C}$. Just before the time to use it add 1 part of $3 \%$ hydroquinone, e.g., $4 \mathrm{ml}$. for the quantities above. (5) At the end of step 3 (incubation with $1 \%$ silver nitrate) pour or suck off the silver nitrate without exposing the preparation to light. Do not wash. Allow the container to cool at $37^{\circ} \mathrm{C}$. (6) Cover the preparations with warm developer, and place the container in enough water at $37^{\circ} \mathrm{C}$. (cf. step 3). Time exactly 10 minutes. (7) Pour or suck off developer. It is usually a translucent pale yellowbrown colour. Wash slides with two changes of warm buffer without exposing to light. Sections may now be examined microscopically if required. If staining is satisfactory, place in $5 \%$ hypo for 5 minutes. (8) Wash well. Counterstain with haematoxylin and eosin or other stains. Dehydrate and mount as usual.

The main factors found to be important for success were as follows:

Impregnation of the tissue with silver nitrate and subsequent development must be at an accurately controlled $p \mathrm{H}$ of 3.6 . Results were relatively irregular unless the solutions of reagents were adjusted carefully to the correct $p \mathrm{H}$ at the reacting temperature; it was insufficient to dissolve the reagents in buffer at $p \mathrm{H} \mathrm{3.6.}$

Development after impregnation follows photographic principles. Hence exposure to light will produce precipitates very rapidly. The whole of the process is carried out in the dark.

There is a time-temperature relationship for both the impregnation and the development. It is clear that the total amount of reducing material to which the reagents are added will depend on the nature of the tissue, the size of the section, and the number of sections stained together in a container. Some adjustment of times may be required to allow for individual conditions. The times recommended have been used successfully for sections of human liver and gingiva; liver, kidney, brain, lung, omentum and skin from guinea-pigs and mice, and for coverslips to which adhered tissue-cultured peritoneal and pulmonary phagocytic cells from rabbits, guinea-pigs, and mice.

Preparation of the developer must proceed as directed. On addition of the silver nitrate to the gelatin, a faint turbidity, probably of silver chloride, is produced with suitable gelatins. The density of this precipitate and the results obtained depend on the rate of combination of the reagents.

Not all gelatins are suitable. Some contain sulphite as a preservative, which also is a reducing agent interfering with the developer. Different batches of bacteriological gelatin (no. 02-158 from Baltimore Biological Laboratory, Inc., 1640 Gorsuch Avenue, Baltimore, Maryland, U.S.A.) have been found suitable. They give a clear almost colourless solution in the buffer and after addition of the silver nitrate. Other gelatins containing sulphite (e.g. 'Bacteriological Gelatine' from Davis Gelatine (Australia) Pty. Ltd., Sydney, Australia) have been used successfully after preliminary treatment. Three ml. of $10 \mathrm{vol} . \mathrm{H}_{2} \mathrm{O}_{2}$ was added to a solution of $5 \mathrm{~g}$. gelatin in $92 \mathrm{ml}$. deionized water; the mixture was boiled for five min. and cooled. 

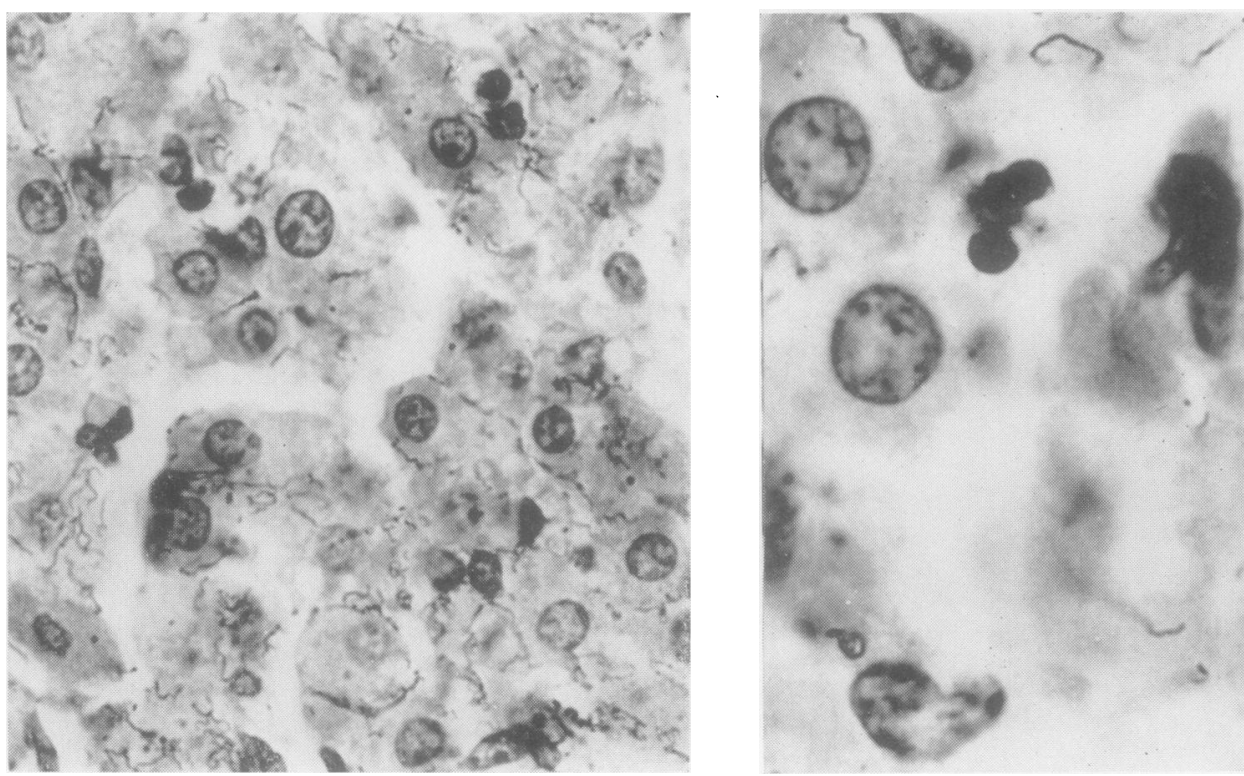

FIG. 1. A section of liver from a guinea-pig which died from infection with Leptospira icterohaemorrhagia兒 stained by the method described, to show spirochaetes and histological detail $(A, \times 530 ; B, \times 1,250)$.

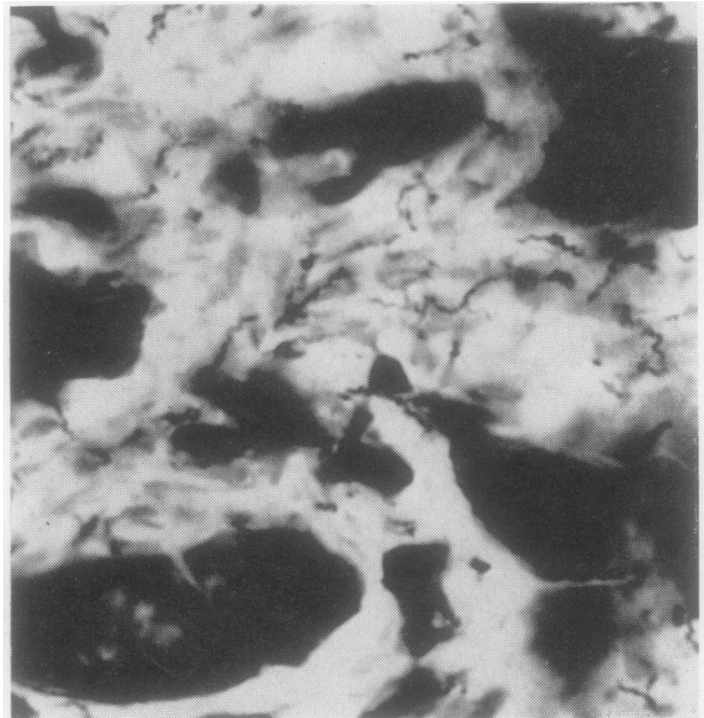

FIG. 2. A section of liver from a syphilitic patient, stained by the silver method described, showing Treponema pallidum in the tissues $(\times 1,250)$.

Four ml. of $M / 5$ acetate buffer was added to give a final concentration of $\mathrm{M} / 125$. Optimum development time was eight min. with this gelatin.

The use of fixatives other than formalin has given variable results. Fixation in liquid air and in cold acetone resulted in much thinner spirochaetes, visible only by searching carefully using oil-immersion magnifications of $\times 1,000$.

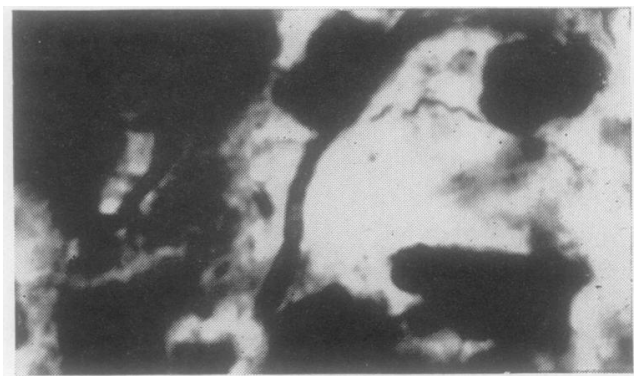

FIG. 3. A necrotic area in a section of human gingivă tissue, showing a spirochaete, bacteria, and tissue cell stained by the method described $(\times 1,250)$.

Well-stained spirochaetes are not always so black that they can be seen at low magnifications. High-power dri $(\times 40)$ objectives and even searching under oil-imo mersion may be necessary to find sparsely-distributef spirochaetes. A representative section from an experis mental leptospiral infection is shown in Figure 1. This spirochaetes are obvious among the tissue cells. There is no granular precipitate to confuse interpretation, an\& tissue detail is plainly visible stained by haematoxylfe and eosin.

I am grateful to Mrs. Isa Melamed, Mr. A. Y. Hynes, and Mr. K. Clifford for their help.

\section{REFERENCES}

Carleton, H. M., and Drury, R. A. B. (1957). Histological Technique 3rd ed., p. 287. Oxford University Press, London.

Faine, S. (1957). Brit. J. exp. Path., 38, 1.

Faulkner, R. R., and Lillie, R. D. (1945). Stain Technol., 20, 81. 